\title{
4-Octyl itaconate (4-OI) attenuates lipopolysaccharide-induced acute lung injury by suppressing PI3K/Akt/NF-кB signaling pathways in mice
}

\author{
YAN XIN $^{1 *}$, LILI ZOU ${ }^{2 *}$ and SHUHUI LANG ${ }^{2}$ \\ ${ }^{1}$ Department of Anesthesiology, Changchun Maternity Hospital, Changchun, Jilin 130042; \\ ${ }^{2}$ Department of Anesthesiology, General Hospital of Ning Xia Medical University, Yin Chuan, Ningxia 750004, P.R. China
}

Received June 4, 2020; Accepted November 17, 2020

DOI: $10.3892 /$ etm.2020.9573

\begin{abstract}
The progression of acute lung injury (ALI) is attributable to inflammation and oxidative stress. The cell-permeable itaconate analog 4-octyl itaconate (4-OI) provides protection against inflammatory responses and oxidative stress. However, whether 4-OI can protect against ALI remains poorly understood. The aim of this study was to explore the protective effects of 4-OI against LPS-induced ALI and the underlying mechanisms using hematoxylin and eosin (H\&E) to observe lung morphology, ELISA and reverse transcription-quantitative PCR to measure the levels of IL-1 $\beta$, TNF- $\alpha$ and IL- 6 and western blotting to examine the levels of PI3K, Akt and NF- $\mathrm{B}$. The present study demonstrates that intraperitoneal administration of $4-\mathrm{OI}(25 \mathrm{mg} / \mathrm{kg}) 2 \mathrm{~h}$ before lipopolysaccharide (LPS; $5 \mathrm{mg} / \mathrm{kg}$ ) intratracheal injection significantly alleviated the lung tissue injury induced by LPS, reducing the production of proinflammatory cytokines and reactive oxygen species (ROS) in vivo. Furthermore, 4-OI and the antioxidant N-acetyl-L-cysteine markedly suppressed PI3K and Akt phosphorylation in LPS-treated RAW264.7 macrophage cells in vitro. Further study demonstrated that a pharmacological inhibitor of the phosphoinositide 3-kinase (PI3K)-Akt pathway, LY294002, inhibited the expression of NF- $\mathrm{NB}$ p65 in the nuclear fraction and decreased the production of inflammatory cytokines. Collectively, the experimental results of the present study provide evidence that 4-OI significantly decreased LPS-induced lung inflammation by suppressing ROS-mediated PI3K/Akt/NF- $\kappa \mathrm{B}$ signaling
\end{abstract}

Correspondence to: Dr Shuhui Lang, Department of Anesthesiology, General Hospital of Ning Xia Medical University, 804 Shengli South Street, Yin Chuan, Ningxia 750004, P.R. China E-mail: 1sh8028@163.com

${ }^{*}$ Contributed equally

Key words: 4-octyl itaconate, acute lung injury, inflammation, oxidative stress pathways. These results suggest that 4-OI could be a valuable therapeutic drug in the treatment of ALI.

\section{Introduction}

Acute lung injury (ALI) is a life-threatening disease characterized by increased vascular permeability and inflammation. Acute respiratory distress syndrome (ARDS) is a serious form of ALI that is associated with multiple organ failure and high mortality among patients in the intensive care unit (1). ARDS may be caused by sepsis, pneumonia, pancreatitis and trauma (2). Although pharmacological interventions and ventilatory management are used to treat ARDS, $40 \%$ of patients with ARDS die in hospitals (3). There are no effective pharmacological therapies for ALI. Therefore, it is urgent to identify valid therapeutic drugs for the improvement of ALI treatment.

Lipopolysaccharide (LPS) has often been used in some animal models of ALI to induce pulmonary inflammation (4). Membrane-bound Toll-like receptors (TLRs) have been demonstrated to play an important role in the innate immune system by recognizing specific damage-associated molecular patterns (DAMPs) and pathogen-associated molecular patterns (PAMPs) of invading microorganisms (5). TLR4 is widely expressed in various immune cells. When LPS binds to TLR4, it contributes to the activation of NF- $\kappa \mathrm{B}$, eventually leading to the production of proinflammatory cytokines (6-8). Many studies have shown that oxidative stress plays a major role in LPS-induced ALI. ROS are mainly generated by NADPH oxidase (Nox), which expands inflammation by activating downstream signal cascades $(9,10)$. A body of evidence indicates that LPS can stimulate the production of ROS, which promotes diverse intracellular responses via the $\mathrm{NF}-\kappa \mathrm{B}$ pathway (11).

Itaconate, as a derivate of the tricarboxylic acid cycle, is derived from the decarboxylation of cis-aconitate mediated by immunoresponsive gene 1 in the mitochondrial matrix (12). It has been reported that itaconate has a direct antimicrobial effect by inhibiting isocitrate lyase (13). Itaconate markedly alleviated skin inflammation in a mouse model of psoriasis and decreased the production of proinflammatory mediators in LPS-treated macrophages $(14,15)$. However, whether and how 4-OI plays a protective role in LPS-induced ALI remains 
largely unknown. In the present study, the protective effects of 4-OI against LPS-induced ALI were investigated, as well as the mechanisms associated with inflammation and oxidative stress in mice.

\section{Materials and methods}

Ethics statement. All animal procedures and experiments were approved by the Institutional Animal Care and Use Committee of Ningxia Medical University [registration no. SCXK (Ning) 2018-0025], where experiments were performed in accordance with the Guide for the Care and Use of Laboratory Animals published by the National Institutes of Health, 8th edition (16).

Drugs and antibodies. 4-OI was obtained from MedChemExpress. Polyclonal antibodies against phosphory-

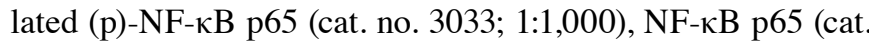
no. 8242; 1:1,000), phospho-PI3K (cat. no. 4228; 1:1,000), PI3K (cat. no. 4249; 1:1,000), phospho-Akt (cat. no. 4060; 1:1,000), Akt (cat. no. 4691; 1:1,000), lamin B (cat. no. 9087; 1:1,000) and $\beta$-actin (cat. no. 4970; 1:1,000), anti-rabbit IgG, and horseradish peroxidase (HRP)-linked antibody (cat. no. 7074; 1:10,000) were purchased from Cell Signaling Technology, Inc. $\mathrm{N}$-acetyl-L-cysteine (NAC) and the PI3K inhibitor LY294002 were provided by Beyotime Institute of Biotechnology. LPS (Escherichia coli 055:B5) was purchased from Sigma-Aldrich (Merck KGaA).

Animals and treatment. Male C57BL/6 mice (20-25 g; 8 weeks old) were used in this study. Mice $(n=15)$ were randomly assigned into three groups of five mice each: Control group, ALI group, and ALI + 4-OI group. According to a previous study (17), mice were anaesthetized with $2 \%$ sodium pentobarbital ( $80 \mathrm{mg} / \mathrm{kg}$; Sigma-Aldrich; Merck KGaA) by intraperitoneal (i.p.) injection. Mice were then treated with an intratracheal (i.t.) injection of LPS (E. coli O111:B4; $5 \mathrm{mg} / \mathrm{kg}$ ) in $50 \mu \mathrm{l}$ saline. Mice in the ALI + 4-OI group received an i.p. injection of 4-OI ( $25 \mathrm{mg} / \mathrm{kg} / \mathrm{dose})$ in (2-hydroxypropyl)$\beta$-cyclodextrin in phosphate-buffered saline (PBS) or vehicle control $2 \mathrm{~h}$ before i.t. injection of LPS, as previously described (18). Control animals received the same volume of vehicle (vehicle group). Lung tissue was harvested for subsequent experiments $12 \mathrm{~h}$ after LPS administration. Mice were anesthetized with inhaled isoflurane (1.5-4\%) and euthanized by exsanguination through right ventricle aspiration, followed by cervical dislocation.

Histological examination. Mice were sacrificed $12 \mathrm{~h}$ after LPS administration. The left lungs of mice were harvested and fixed with $4 \%$ paraformaldehyde at $25^{\circ} \mathrm{C}$ for $24 \mathrm{~h}$. After fixation, lung tissue was embedded in paraffin and sectioned at $5-\mu \mathrm{m}$ thickness. The sections were stained with hematoxylin at $25^{\circ} \mathrm{C}$ for $10 \mathrm{~min}$ and eosin $(\mathrm{H} \& \mathrm{E})$ at $25^{\circ} \mathrm{C}$ for $3 \mathrm{~min}$ and visualized under a light microscope (magnification, x200). Morphological changes and injury were scored as follows: 0 , no injury; 1, mild; 2, moderate; and 3, severe injury. This scoring system was based on the presence of exudates, hyperemia or congestion, infiltration of neutrophils, alveolar hemorrhage, presence of debris, and cellular hyperplasia (19).
Lung wet/dry (W/D) weight ratios. The lung W/D ratio was calculated as an indicator of pulmonary edema. The right upper lung of each mouse was excised for the determination of wet weight and then placed in an $80^{\circ} \mathrm{C}$ oven for 4 days and reweighed to determine its dry weight.

Bronchoalveolar lavage fluid (BALF) acquisition and analysis. After the mice were sacrificed, the BALF was harvested by three i.t. injections of $0.5 \mathrm{ml}$ cooled PBS. The harvested fluid was centrifuged for $10 \mathrm{~min}$ at $1500 \mathrm{x} \mathrm{g}$ at $4^{\circ} \mathrm{C}$. Total cell, neutrophil and macrophage counts were counted with a hemocytometer and Wright-Giemsa staining at $25^{\circ} \mathrm{C}$ for $30 \mathrm{sec}$. The supernatant was collected for total protein content detection and cytokine examination.

$R N A$ extraction and reverse transcription-quantitative (RT-q) $P C R$. Total RNA isolated from lung tissue using TRIzol ${ }^{\circledR}$ (Applied Biosystems; Thermo Fisher Scientific, Inc.) and reverse-transcribed with random hexamers and MultiScribe ${ }^{\mathrm{TM}}$ reverse transcriptase (Applied Biosystems; Thermo Fisher Scientific, Inc.) at $50^{\circ} \mathrm{C}$ for $15 \mathrm{~min}$ and then at $85^{\circ} \mathrm{C}$ for $5 \mathrm{sec}$. qPCR was performed using HiScript ${ }^{\circledR}$ II One Step qRT PCR kit (Vazyme Biotech, Co., Ltd.) on a deep-well Real-Time PCR Detection system (CFX96 Touch ${ }^{\mathrm{TM}}$; Bio-Rad Laboratories, Inc.) using the following thermocycling conditions: Initial denaturation at $95^{\circ} \mathrm{C}$ for $5 \mathrm{~min}$, followed by 35 cycles of denaturation at $94^{\circ} \mathrm{C}$ for $60 \mathrm{sec}$, annealing at $58^{\circ} \mathrm{C}$ for $60 \mathrm{sec}$ and extension at $72^{\circ} \mathrm{C}$ for $50 \mathrm{sec}$. The relative expression level of the target gene was examined using the comparative $2^{-\Delta \Delta \mathrm{Cq}}$ method (20). $\beta$-actin mRNA served as an internal control. The following mouse primers were used: Interleukin (IL)- $1 \beta$ forward, 5'-GGGCCTCAAAGGAAAGAATC-3' and reverse, 5'-TACCAGTTGGGGAACTCTGC-3'; tumor necrosis factor (TNF)- $\alpha$ forward, 5'-ACAGCAAGGGACTAGCCAGGAG-3' and reverse, 5'-GGAGTGCCTCTTCTGCCAGT-3'; IL-6 forward, 5'-CTGGGGATGTCTGTAGCTCA-3' and reverse, 5'-CTGTGAAGTCTCCTCTCCGG-3'; inducible nitric oxide synthase (iNOS) forward, 5'-TTTGTGCGAAGTGTCAGTGG-3' and reverse, 5'-AGAAACTTCGGAAGGGAGCA-3'; $\beta$-actin forward, 5'-GTGGACATCCGCAAAGAC-3' and reverse, 5'-AAAGGGTGTAACGCAACTA-3'.

Cell culture. RAW264.7 murine macrophage-like cells, purchased from the CBCAS (The Cell Bank of Type Culture Collection of The Chinese Academy of Sciences), were cultured in DMEM (Invitrogen; Thermo Fisher Scientific, Inc.) containing $10 \%(\mathrm{v} / \mathrm{v})$ fetal bovine serum (FBS, Gibco; Thermo Fisher Scientific, Inc.) in a humidified atmosphere of $5 \% \mathrm{CO}_{2}$ at $37^{\circ} \mathrm{C}$. RAW264.7 cells were pretreated with 4-OI $(125 \mu \mathrm{M})$, NAC (10 mM), the PI3K inhibitor LY294002 $(25 \mu \mathrm{M})$ or vehicle control for $1 \mathrm{~h}$ and then stimulated with LPS $(1 \mu \mathrm{g} / \mathrm{ml})$ at $37^{\circ} \mathrm{C}$ for $30 \mathrm{~min}$ to detect the phosphorylated levels of PI3K, AKT and p65 in LPS-treated macrophages and at $37^{\circ} \mathrm{C}$ for $24 \mathrm{~h}$ to quantify the concentration of TNF- $\alpha, \mathrm{IL}-1 \beta$, and IL- 6 in macrophages. The dose and treatment duration of all drugs were selected according to previous studies $(21,22)$.

Reactive oxygen species (ROS)-generation assay. After the mice were sacrificed, the BALF was harvested and lysed 
A

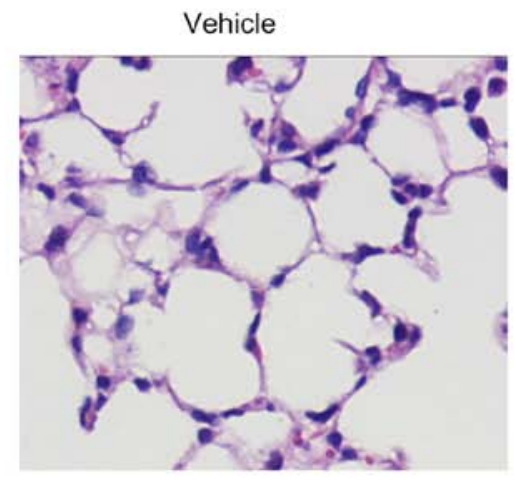

B

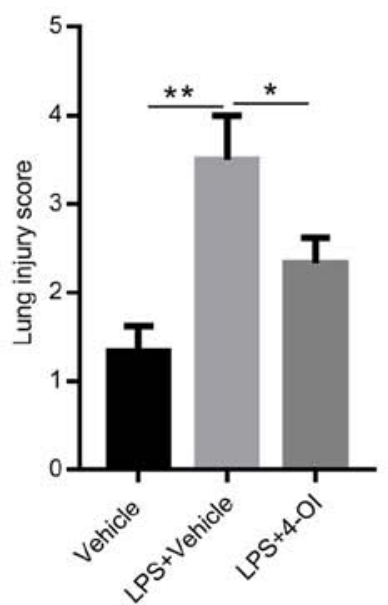

LPS+Vehicle

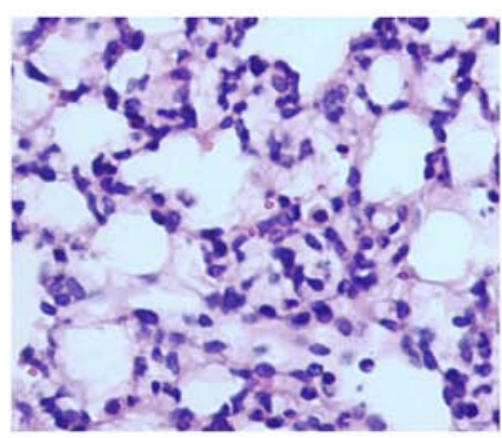

C

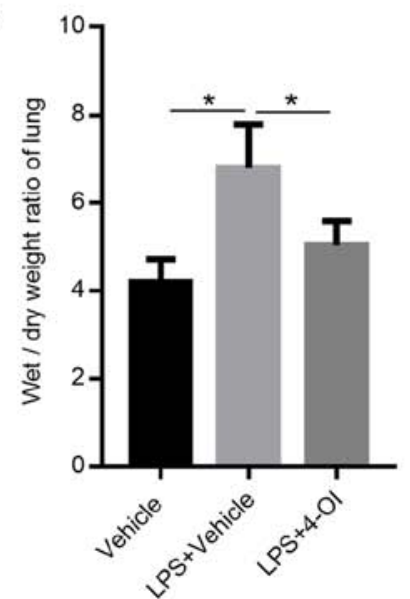

LPS+4-OI

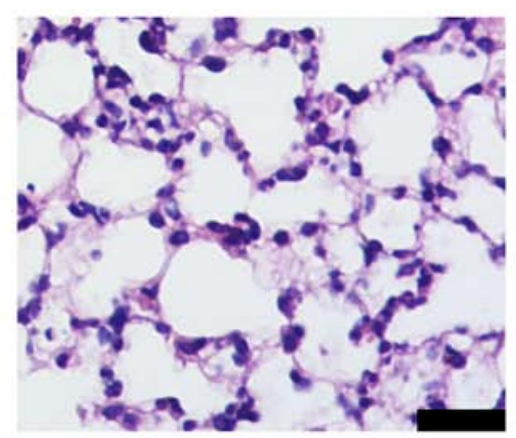

D

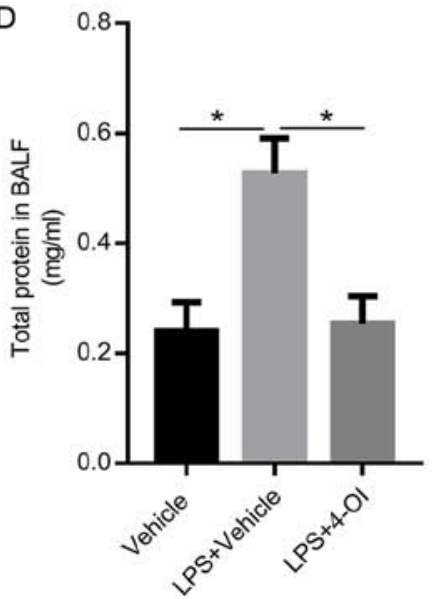

Figure 1. 4-OI alleviates lung injury induced by LPS in mice. Treatment of mice with 4-OI at doses of $25 \mathrm{mg} / \mathrm{kg}$ was administered intraperitoneally, and the control group received an equivalent volume of vehicle [(2-hydroxypropyl)- $\beta$-cyclodextrin in phosphate-buffered saline (PBS)] $2 \mathrm{~h}$ before saline or LPS injection $(5 \mathrm{mg} / \mathrm{kg}$, intratracheal). Twelve hours later, the mice were sacrificed. Hematoxylin and eosin staining (A, bar=100 $\mu \mathrm{m})$ was used to detect the lung histopathological changes. (B) Lung injury scores were determined using four independent parameters, namely alveolar congestion, hemorrhage, leukocyte infiltration and alveolar wall thickness. The lung wet/dry ratio (C) and total protein in BALF (D) were measured to determine lung permeability ( $\mathrm{n}=5$ ). Data are expressed as the mean \pm SEM. " $\mathrm{P}<0.05$ and ${ }^{* *} \mathrm{P}<0.01$. 4-OI, 4-octyl itaconate; LPS, lipopolysaccharides; BALF, bronchoalveolar lavage fluid.

by Ammonium-Chloride-Potassium Lysis buffer (Beyotime Institute of Biotechnology). To detect ROS generation, the sedimented cells were resuspended in PBS. Briefly, the cells were incubated with $50 \mu \mathrm{M}$ of DCFH-DA for 30 min at $37^{\circ} \mathrm{C}$ in darkness. DCF fluorescence intensities were measured by flow cytometry. At the end of the treatment, the cells were incubated with $10 \mu \mathrm{M}$ dichloro-dihydrofluorescein diacetate (DCFH-DA; Beyotime Institute of Biotechnology) for $1 \mathrm{~h}$ at $37^{\circ} \mathrm{C}$ in the dark. ROS generation in the cells was measured immediately using a fluorescence microscope (magnification, x200; Nikon Corporation). Myeloperoxidase (MPO) activity, malondialdehyde (MDA) content, superoxide dismutase (SOD) activity, and glutathione (GSH) content were also measured. The lung homogenate was dissolved in extraction buffer to detect the levels of MPO, MDA, SOD and GSH using commercially available assay kits (cat. nos. A044-1-1, A0031-2, A001-3-2 and A005-1-2, respectively; Nanjing Jiancheng Bioengineering Institute), according to the manufacturer's instructions.

Cytokine measurements. Cytokines in serum were measured using enzyme-linked immunosorbent assay (ELISA). Commercially available ELISA kits (IL-1 $\beta$; cat. no. MLB00C; IL-6; cat. no. M6000B; TNF- $\alpha$, cat. no. MTA00B; R\&D
Systems, Inc.) were used to determine the levels of IL-1 $\beta$, TNF- $\alpha$ and IL-6, as previously described $(23,24)$.

Extraction of nuclear and cytosolic proteins. To extract nuclear and cytosolic proteins, cells were washed and lysed with hypotonic buffer [20 mM Hepes ( $\mathrm{pH} 8.0$ ), $10 \mathrm{mM} \mathrm{KCl,} 1 \mathrm{mM}$ EDTA, $1.5 \mathrm{mM} \mathrm{MgCl}{ }_{2}, 1 \mathrm{mM}$ DTT, $1 \mathrm{mM} \mathrm{Na} \mathrm{VO}_{4}, 1 \mathrm{mM}$ $\mathrm{NaF}, 1 \mathrm{mM}$ PMSF and $1 \%(\mathrm{v} / \mathrm{v})$ protease inhibitor cocktail] on ice for $30 \mathrm{~min}$. NP-40 (0.625\%) was added to cell lysates. The lysates were collected and centrifuged at $13000 \mathrm{xg}$ and $4^{\circ} \mathrm{C}$ for $15 \mathrm{~min}$. The supernatants served as the cytosolic extract. The nuclear pellets were resuspended in cold buffer for another $30 \mathrm{~min}$ and centrifuged at $15000 \mathrm{x} \mathrm{g}$ and $4^{\circ} \mathrm{C}$ for $5 \mathrm{~min}$, and the supernatants were collected as the nuclear extract.

Western blotting. Proteins were extracted with RIPA Lysis Buffer (Beyotime Institute of Biotechnology) from the cells with protein concentration determined using bicinchoninic acid protein assay. Equal amounts of protein (30 $\mu \mathrm{g})$ were loaded onto $10 \%$ SDS-polyacrylamide gels and transferred onto polyvinylidene fluoride (PVDF) membranes. The blots were blocked with $5 \%$ dry milk in Tris-buffered saline with $0.1 \%$ Tween-20 at $25^{\circ} \mathrm{C}$ for $30 \mathrm{~min}$ and incubated with the appropriate primary antibody overnight at $4^{\circ} \mathrm{C}$. The 

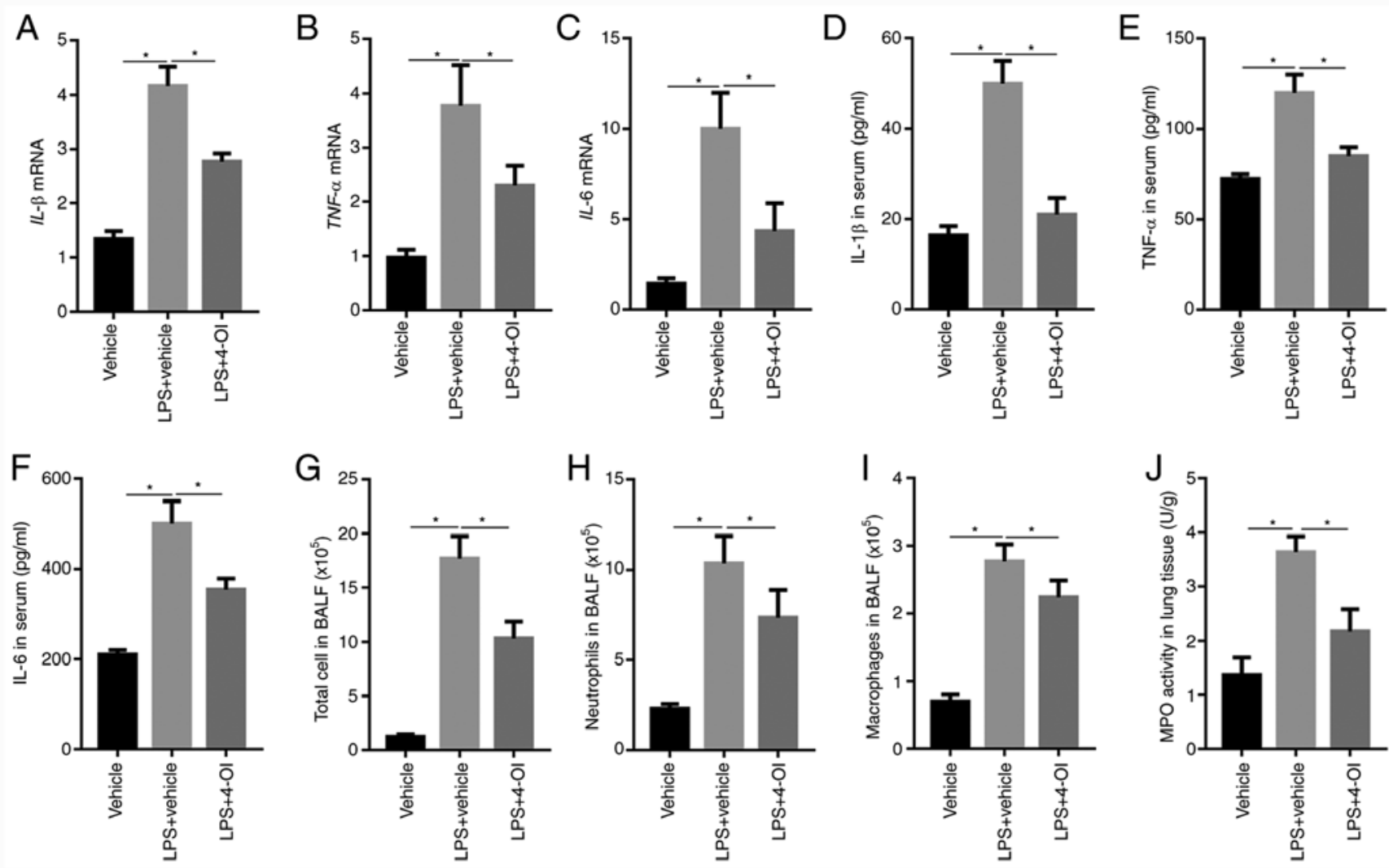

Figure 2. 4-OI inhibits LPS-induced inflammatory responses in mice with acute lung injury. Treatment of mice with $4-\mathrm{OI}$ at doses of $25 \mathrm{mg} / \mathrm{kg}$ was administered intraperitoneally, and the control group received an equivalent volume of vehicle [(2-hydroxypropyl)- $\beta$-cyclodextrin in phosphate-buffered saline (PBS)] $2 \mathrm{~h}$ before saline or LPS injection (5 mg/kg, intratracheal). Twelve hours later, IL-1 $\beta$ (A), TNF- $\alpha$ (B), and IL-6 (C) mRNA levels in the lungs were determined by reverse transcription-quantitative PCR (n=5). IL-1 $\beta$ (D), TNF- $\alpha(E)$, and IL-6 (F) protein contents in serum were determined by enzyme-linked immunosorbent assay $(n=5)$. Twelve hours later, total cells $(\mathrm{G})$, neutrophils $(\mathrm{H})$ and macrophages (I) in BALF were assessed ( $\mathrm{n}=5)$. MPO activity $(\mathrm{J})$ in lung tissue was determined $(\mathrm{n}=5)$. Data are expressed as the mean \pm SEM. "P<0.05. 4-OI, 4-octyl itaconate; LPS, lipopolysaccharides; IL, interleukin; TNF, tumor necrosis factor; BALF, bronchoalveolar lavage fluid; MPO, myeloperoxidase.

blots were washed three times and then incubated with an HRP-conjugated secondary antibody at $25^{\circ} \mathrm{C}$ for $1 \mathrm{~h}$. Blots were then visualized using an enhanced chemiluminescence reagent (Bio-Rad Laboratories, Inc.). Images were acquired using ImageQuant LAS 4000 mini (Cytvia).

Statistical analysis. All data are normally distributed and are expressed as the means \pm SEM. Differences among multiple groups were analyzed by one-way ANOVA with Tukey's post hoc test. For the comparison of lung scoring, Kruskal-Wallis test followed by Dunn's multiple comparison test was used. $\mathrm{P}<0.05$ was considered to indicate a statistically significant difference.

\section{Results}

4-OI ameliorates lung tissue injury in mice with LPS-induced $A L I$. To confirm the role of 4-OI in the progression of LPS-induced ALI, cells were pretreated with a dose of 4-OI ( $25 \mathrm{mg} / \mathrm{kg} /$ dose; i.p.) before i.t. injection of LPS in mice. The results demonstrated that LPS led to severe inflammatory histological changes in lung tissues, including inflammatory cell infiltration, damage to the alveolar wall and pulmonary congestion, which were markedly reversed by 4-OI treatment (Fig. 1A). Moreover, compared with that in the LPS group, the lung injury score was decreased in the 4-OI treatment group (Fig. 1B). In addition, 4-OI treatment significantly decreased the W/D ratios (Fig. 1C) and the total protein concentration in BALF (Fig. 1D) compared with those in the LPS group, which are two indicators of pulmonary edema.

4-OI suppresses inflammatory responses in LPS-induced ALI in mice. Subsequently, the effects of 4-OI on LPS-induced intrapulmonary inflammatory responses were determined in mice. The results showed that pretreatment with 4-OI decreased the gene expression and secretion of IL-1 $\beta$, TNF- $\alpha$ and IL-6 in the lungs (Fig. 2A-F). Furthermore, pretreatment with 4-OI notably decreased the number of total cells, neutrophils and macrophages in BALF induced by LPS (Fig. 2G-I). In addition, pretreatment with 4-OI effectively decreased the LPS-induced increase in MPO activity, which is a marker of neutrophil infiltration in lung tissues (Fig. 2J). These results illustrated that 4-OI prevented LPS-induced ALI by inhibiting inflammatory responses.

4-OI decreases oxidative stress in mice with LPS-induced ALI. Given that oxidative stress plays an important role in ALI, whether 4-OI could decrease oxidative stress induced by LPS was determined. The results showed that LPS increased ROS generation in the BALF of ALI mice and MDA formation in 
A
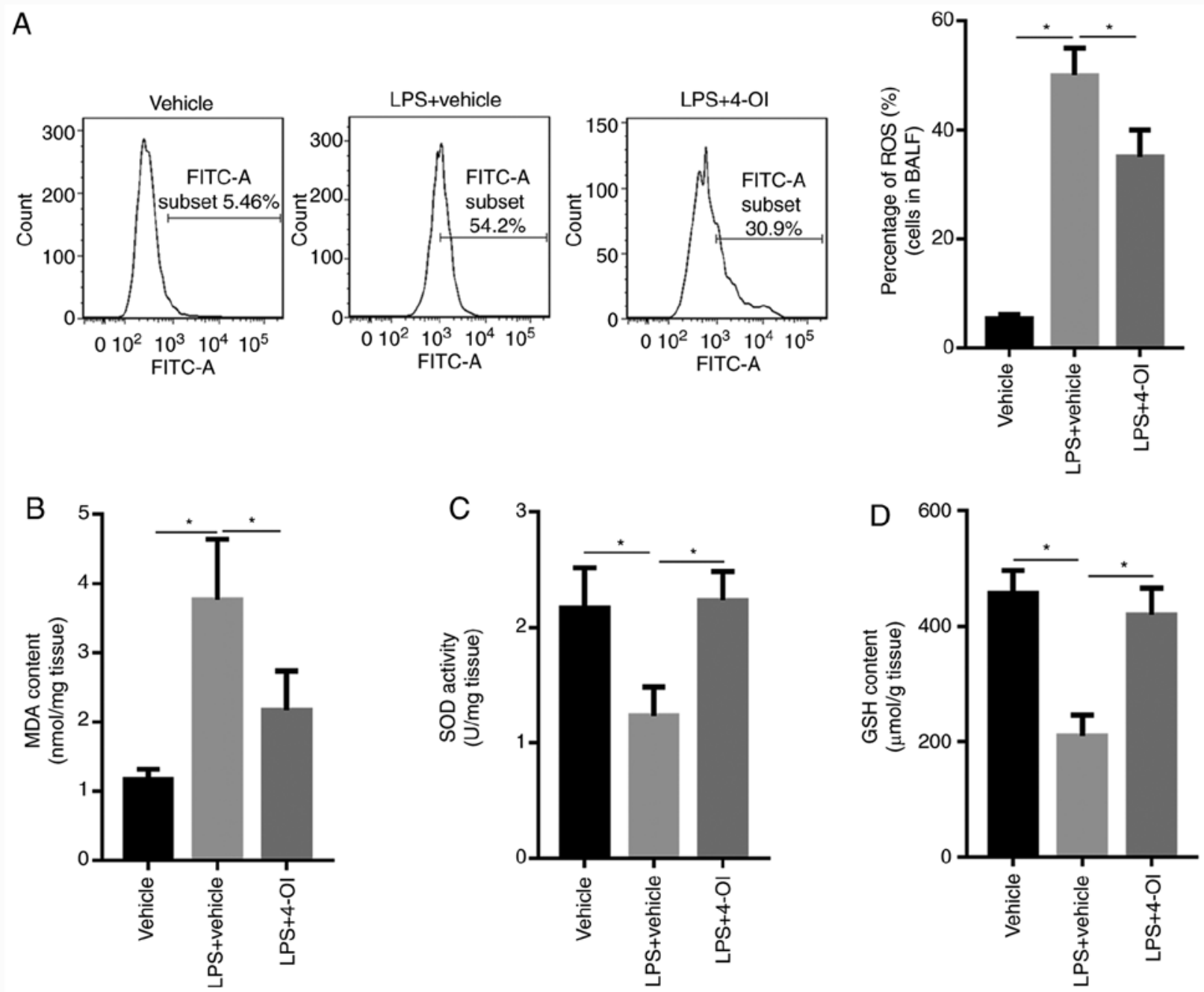

Figure 3. 4-OI inhibited oxidative stress in LPS-induced acute lung injury mice. Treatment of mice with 4-OI at doses of $25 \mathrm{mg} / \mathrm{kg}$ was administered intraperitoneally, and the control group received an equivalent volume of vehicle [(2-hydroxypropyl)- $\beta$-cyclodextrin in phosphate-buffered saline (PBS)] $2 \mathrm{~h}$ before saline or LPS injection (5 mg/kg, intratracheal). In total, $12 \mathrm{~h}$ later, ROS generation (A) in the BALF, MDA content (B), SOD activity (C) and GSH content (D) in lung tissue were determined ( $\mathrm{n}=5$ ). Data are expressed as the mean \pm SEM. "P<0.05. 4-OI, 4-octyl itaconate; LPS, lipopolysaccharides; ROS, reactive oxygen species; MDA, malondialdehyde; SOD, superoxide dismutase; GSH, glutathione.

the lung tissue of ALI mice, which were inhibited by 4-OI treatment (Fig. 3A and B). Since increased levels of SOD and GSH could inhibit oxidative stress, the levels of SOD and GSH were detected by ELISA. The results showed that LPS decreased the levels of SOD and GSH in the lung tissue of ALI mice, and this effect was significantly reversed by pretreatment with 4-OI (Fig. 3C and D). These results indicate that pretreatment with 4-OI could decrease oxidative stress in the lung tissue of ALI mice.

4-OI decreases the production of inflammatory cytokines by inhibiting ROS-mediated PI3K/Akt/NF- $\kappa B$ activation. Growing evidence has demonstrated that ROS can activate the PI3K/Akt pathway, which further induces NF- $\mathrm{KB}$ translocation from the cytosol into the nucleus (21). Therefore, the phosphorylated levels of PI3K and Akt were detected by western blotting. The results illustrated that LPS increased the phosphorylated levels of PI3K and Akt, which were inhibited by the ROS scavenger NAC and 4-OI (Fig. 4A). To further demonstrate whether PI3K/Akt is involved in the activation of the NF- $\kappa \mathrm{B}$ pathway in LPS-stimulated macrophages, the expression of NF- $\mathrm{kB}$ p65 in the nuclear and cytosolic fractions was detected by western blotting. The results illustrated that LY294002, a specific inhibitor of the PI3K/Akt pathway, significantly inhibited the LPS-induced increased level of NF- $\kappa B$ p65 in the nuclear fraction (Fig. 4B). Moreover, ROS generation and MDA formation were increased in LPS-treated RAW264.7 macrophage cells and were inhibited by 4-OI and NAC treatment (Fig. 4C and D). In addition, the levels of SOD and GSH were decreased in LPS-treated RAW264.7 macrophage cells, and this effect was significantly reversed by pretreatment with 4-OI and NAC (Fig. 4E and F). Furthermore, the production of TNF- $\alpha$, IL- $1 \beta$ and IL- 6 was also decreased by LY294002 (Fig. 4G-L). Collectively, these data demonstrate that 4-OI alleviated LPS-induced ALI by suppressing the ROS-mediated PI3K/Akt/NF- $\kappa \mathrm{B}$ pathway.

\section{Discussion}

Uncontrolled inflammatory responses and/or excessive oxidative stress are deemed to play an important role in the pathogenesis of ALI (25). The present study demonstrated 


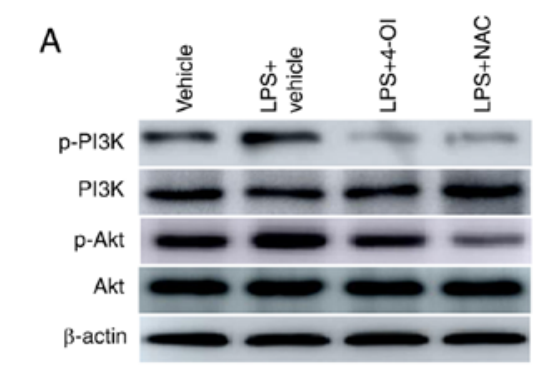

C
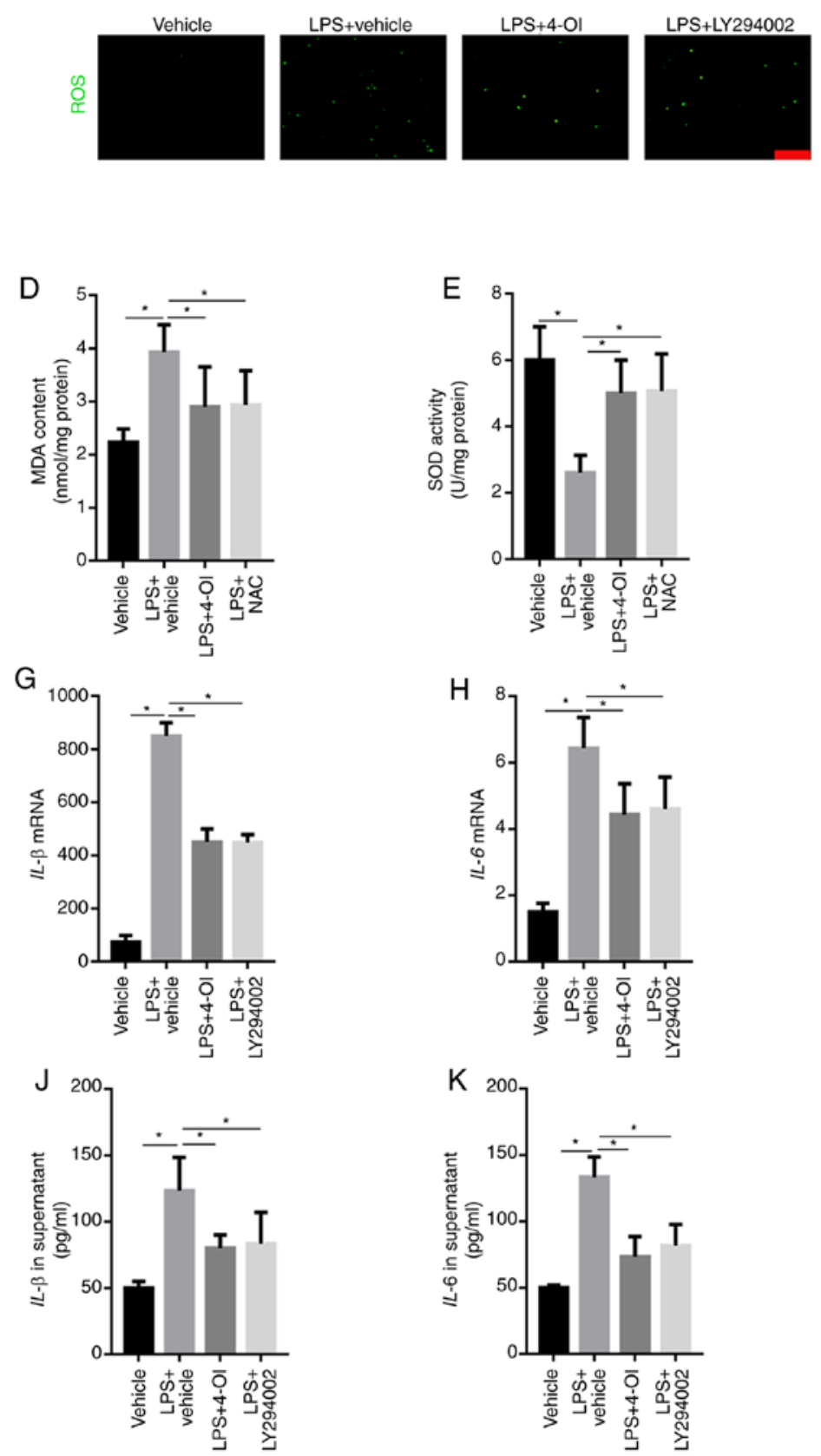
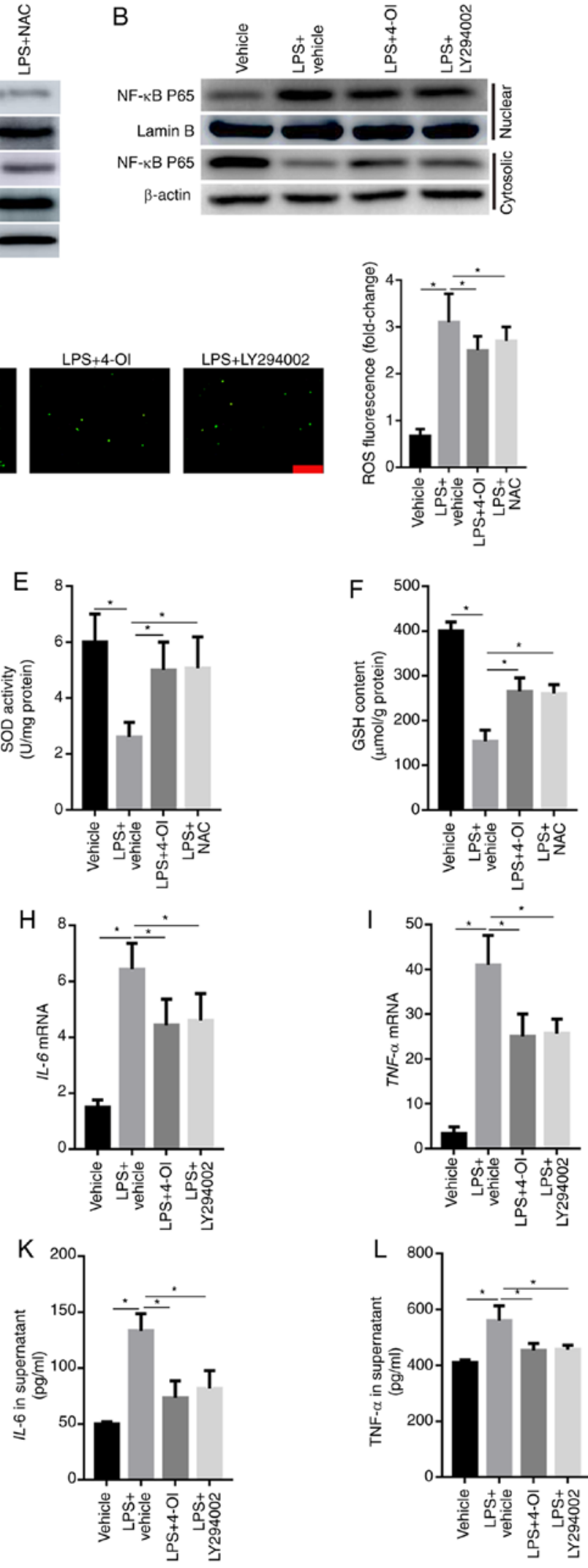
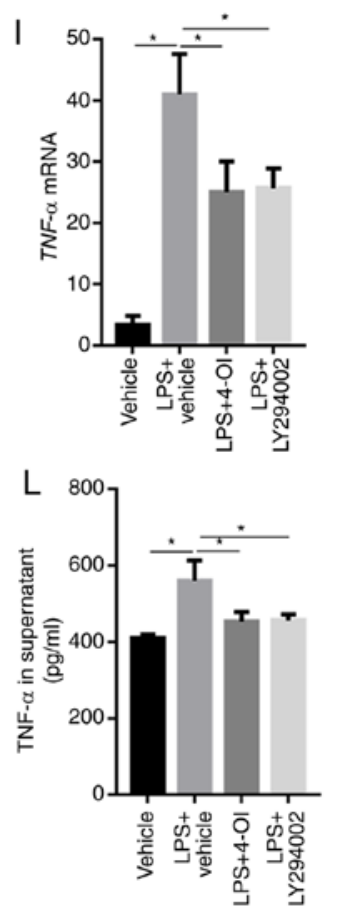

Figure 4. 4-OI decreased the induction of inflammatory cytokines by inhibiting ROS-mediated PI3K/Akt/NF-kB activation in LPS-treated macrophages. RAW264.7 macrophage cells were pretreated with 4-OI $(125 \mu \mathrm{M})$, NAC $(10 \mathrm{mM})$, the PI3K inhibitor LY294002 $(25 \mu \mathrm{M})$ or vehicle control for $1 \mathrm{~h}$ and then stimulated with LPS $(1 \mu \mathrm{g} / \mathrm{ml})$ for 30 min to detect the phosphorylated levels of PI3K and Akt and the expression of NF-kB p65 in the nuclear and cytosolic fractions in LPS-treated macrophages and for $24 \mathrm{~h}$ to quantify ROS production, MDA content, SOD activity and GSH content and the concentration of TNF- $\alpha$, IL-1 $\beta$, and IL-6 in macrophages. The phosphorylated levels of PI3K and Akt (A) and the expression of NF- $\mathrm{kB}$ p65 in the nuclear and cytosolic fractions (B) of LPS-treated macrophages were detected by western blotting. ROS generation (bar=100 $\mu \mathrm{m})(\mathrm{C})$, MDA content (D), SOD activity (E) and GSH content (F) in RAW264.7 macrophage cells were determined. The expression of IL-1 $\beta$ (G), IL-6 (H) and TNF- $\alpha$ (I) in macrophages was measured by qPCR. IL-1 $\beta$ (J), IL-6 $(\mathrm{K})$ and TNF- $\alpha$ (L) protein contents in the supernatant of RAW264.7 macrophage cells were determined. Data represent the means \pm SEM of three independent experiments. " $\mathrm{P}<0.05$. 4-OI, 4-octyl itaconate; LPS, lipopolysaccharides; NAC, N-acetyl-L-cysteine; ROS, reactive oxygen species; MDA, malondialdehyde; SOD, superoxide dismutase; GSH, glutathione; IL, interleukin; TNF, tumor necrosis factor. 
that 4-OI alleviated LPS-induced ALI by inhibiting the inflammatory response and oxidative stress. 4-OI suppressed inflammatory cell infiltration and proinflammatory cytokine generation, decreased lung tissue structural damage, attenuated ROS generation and inhibited NF- $\kappa \mathrm{B}$ activation in LPS-induced ALI mice in vivo. These results illustrate that 4-OI may be selected as an effective drug for the treatment of ALI in the future.

It has been reported that 4-OI attenuates hepatic I/R injury in vivo and protects hepatocytes from injury resulting from $\mathrm{H} / \mathrm{R}$ in vitro (18). In addition, octyl itaconate (OI) markedly prolonged survival, improved body temperature regulation, decreased the clinical score, and reduced TNF and IL- $1 \beta$ levels in an LPS model of sepsis by activating the anti-inflammatory transcription factor Nrf2 (also known as NFE2L2) (15). Itaconate alkylates cysteine residues of KEAP1 protein, a central player in the antioxidant response, enabling Nrf2 to accumulate, migrate to the nucleus and further increase the expression of downstream genes with anti-inflammatory and antioxidant capacities (26). Moreover, OI ameliorated renal fibrosis by inhibiting NF- $\kappa \mathrm{B}$ activation, decreasing the generation of ROS and suppressing autophagy (27). Whether 4-OI can protect against ALI remains unknown. The present study aimed to explore the protective effects of 4-OI against ALI in mice, and it was demonstrated that 4-OI could attenuate the inflammatory cell infiltration, $\mathrm{NF}-\kappa \mathrm{B}$ activation and oxidative stress induced by LPS. However, the exact mechanism needs to be further investigated. LPS binds to TLR4, which initiates two classic pathways. One pathway is toll/IL-1 receptor domain-containing adaptor including interferon- $\beta$-dependent, requiring the toll/IL-1 receptor (TIR) domain-containing adaptor protein. The other pathway is MyD88-dependent and promotes the translocation of $\mathrm{NF}-\kappa \mathrm{B}$ from the cytosol into the nucleus, leading to the release of proinflammatory cytokines (28). The excessive release of proinflammatory cytokines by activated macrophages aggravates tissue injury (29). In the present study, it was observed that treatment with 4-OI significantly decreased the LPS-induced expression of IL-1 $\beta$, IL-6 and TNF- $\alpha$ in lung tissue.

Oxidative stress modulated by ROS plays an essential role in the progression of ALI (30). Under physiological conditions, ROS can help prevent pathological injury or noxious stimulation. However, excessive generation of ROS is thought to lead to cellular injury and oxidative stress (9). In the present study, it was found that treatment with 4-OI significantly decreased LPS-induced ROS generation and MDA formation and reversed the LPS-induced decrease in SOD and GSH levels in lung tissue.

The PI3K/Akt pathway plays an important role in cellular defense against inflammatory stimuli (31). Previous studies have also indicated that inhibition of the PI3K/Akt pathway attenuates LPS-induced ALI (32). Moreover, ROS lead to the activation of PI3K/Akt by inactivating the PTEN protein. Furthermore, PTEN inhibits the activation of $\mathrm{NF}-\kappa \mathrm{B}$ via the PI3K/Akt pathway (33). In addition, ROS, as secondary messengers, induce the nuclear translocation of NF- $\kappa \mathrm{B}$ and the production of inflammatory cytokines (34). The present study demonstrated that 4-OI and NAC decreased the LPS-induced production of ROS, and the role of 4-OI in the PI3K/Akt pathway was further explored. In accordance with a previous study (21), the administration of NAC also suppressed the phosphorylated levels of PI3K and Akt in LPS-treated RAW264.7 macrophages. It has been reported that the PI3K and Akt pathways regulate LPS-induced NF- $\kappa \mathrm{B}$ activation (35). Therefore, it was hypothesized that the PI3K/Akt pathway plays a pivotal role in ROS-mediated NF- $\mathrm{B}$ activation. The results demonstrated that LY294002, a specific inhibitor of the PI3K/Akt pathway, markedly inhibited LPS-induced NF- $\kappa \mathrm{B}$ activation. Moreover, LY294002 also decreased the levels of TNF- $\alpha$, IL-1 $\beta$ and IL-6. These results demonstrated that 4-OI decreased the production of inflammatory cytokines by inhibiting the ROS-mediated $\mathrm{PI} 3 \mathrm{~K} / \mathrm{Akt} / \mathrm{NF}-\kappa \mathrm{B}$ pathway.

In conclusion, the present study confirmed that 4-OI exerts potential protective effects against LPS-induced lung injury in mice, possibly through inhibition of the ROS-mediated PI3K/ Akt/NF-кB pathway.

\section{Acknowledgements}

Not applicable.

\section{Funding}

This work was supported by the Natural Science Foundation of Ningxia (grant no. NZ16137).

\section{Availability of data and materials}

All data generated or analyzed during the present study are included in this published article.

\section{Authors' contributions}

SL and YX designed the study. YX and LZ performed all the experiments and analyzed the data. All authors read and approved the final manuscript.

\section{Ethics approval and consent to participate}

The experiments were approved by the Institutional Ethics Committee of Faculty of Ningxia Medical University (Yinchuan, China).

\section{Patient consent for publication}

Not applicable.

\section{Competing interests}

The authors declare that they have no competing interests.

\section{References}

1. Shen Y, Cai G, Chen S, Hu C and Yan J: Fluid intake-related association between urine output and mortality in acute respiratory distress syndrome. Respir Res 21: 24, 2020.

2. Ware LB and Matthay MA: The acute respiratory distress syndrome. N Engl J Med 342: 1334-1349, 2000.

3. el-Ebiary M, Torres A, Fàbregas N, de la Bellacasa JP, González J, Ramirez J, del Baño D, Hernández C and Jiménez de Anta MT: Significance of the isolation of Candida species from respiratory samples in critically ill, non-neutropenic patients. An immediate postmortem histologic study. Am J Respir Crit Care Med 156: 583-590, 1997. 
4. Lv H, Liu Q, Wen Z, Feng H, Deng X and Ci X: Xanthohumol ameliorates lipopolysaccharide (LPS)-induced acute lung injury via induction of AMPK/GSK3 $\beta$-Nrf2 signal axis. Redox Biol 12: 311-324, 2017.

5. Kawai T and Akira S: Toll-like receptors and their crosstalk with other innate receptors in infection and immunity. Immunity 34 : 637-650, 2011

6. Kong L and Ge BX: MyD88-independent activation of a novel actin-Cdc42/Rac pathway is required for Toll-like receptorstimulated phagocytosis. Cell Res 18: 745-755, 2008.

7. Shim JH, Xiao C, Paschal AE, Bailey ST, Rao P, Hayden MS, Lee KY, Bussey C, Steckel M, Tanaka N, et al: TAK1, but not TAB1 or TAB2, plays an essential role in multiple signaling pathways in vivo. Genes Dev 19: 2668-2681, 2005.

8. Badr G, Al-Sadoon MK, El-Toni AM and Daghestani M: Walterinnesia aegyptia venom combined with silica nanoparticles enhances the functioning of normal lymphocytes through PI3K/AKT, NFאB and ERK signaling. Lipids Health Dis 11: 27, 2012.

9. Yang CS, Kim JJ, Lee SJ, Hwang JH, Lee CH, Lee MS and Jo EK: TLR3-triggered reactive oxygen species contribute to inflammatory responses by activating signal transducer and activator of transcription-1. J Immunol 190: 6368-6377, 2013.

10. Hong HY, Jeon WK and Kim BC: Up-regulation of heme oxygenase-1 expression through the Rac1/NADPH oxidase/ROS/ p38 signaling cascade mediates the anti-inflammatory effect of 15-deoxy-delta 12,14-prostaglandin $\mathrm{J} 2$ in murine macrophages. FEBS Lett 582: 861-868, 2008

11. Jiang K, Guo S, Yang C, Yang J, Chen Y, Shaukat A, Zhao G, Wu H and Deng G: Barbaloin protects against lipopolysaccharide (LPS)-induced acute lung injury by inhibiting the ROS-mediated $\mathrm{PI} 3 \mathrm{~K} / \mathrm{AKT} / \mathrm{NF}-\kappa \mathrm{B}$ pathway. Int Immunopharmacol 64: 140-150, 2018.

12. Yu XH, Zhang DW, Zheng XL and Tang CK: Itaconate: An emerging determinant of inflammation in activated macrophages. Immunol Cell Biol 97: 134-141, 2019.

13. Rittenhouse JW and McFadden BA: Inhibition of isocitrate lyase from Pseudomonas indigofera by itaconate. Arch Biochem Biophys 163: 79-86, 1974

14. Bambouskova M, Gorvel L, Lampropoulou V, Sergushichev A, Loginicheva E, Johnson K, Korenfeld D, Mathyer ME, Kim H, Huang LH, et al: Electrophilic properties of itaconate and derivatives regulate the $\mathrm{I} \kappa \mathrm{B}\}-\mathrm{ATF} 3$ inflammatory axis. Nature 556: 501-504, 2018

15. Mills EL, Ryan DG, Prag HA, Dikovskaya D, Menon D, Zaslona Z, Jedrychowski MP, Costa ASH, Higgins M, Hams E, et al: Itaconate is an anti-inflammatory metabolite that activates Nrf2 via alkylation of KEAP1. Nature 556: 113-117, 2018.

16. National Research Council (US) Committee for the Update of the Guide for the Care and Use of Laboratory Animals: Guide for the Care and Use of Laboratory Animals. 8th edition. National Academies Press (US), Washington, DC, 2011.

17. Zhang Y, Xu T, Pan Z, Ge X, Sun C, Lu C, Chen H, Xiao Z, Zhang B, Dai Y, et al: Shikonin inhibits myeloid differentiation protein 2 to prevent LPS-induced acute lung injury. Br J Pharmacol 175: 840-854, 2018.

18. Yi Z, Deng M, Scott MJ, Fu G, Loughran PA, Lei Z, Li S, Sun P, Yang C, Li W, et al: IRG1/itaconate activates Nrf2 in hepatocytes to protect against liver ischemia-reperfusion injury. Hepatology: Jan 30, 2020 (Epub ahead of press).

19. Aziz M, Matsuda A, Yang WL, Jacob A and Wang P: Milk fat globule-epidermal growth factor-factor 8 attenuates neutrophi infiltration in acute lung injury via modulation of CXCR2. J Immunol 189: 393-402, 2012.

20. Livak KJ and Schmittgen TD: Analysis of relative gene expression data using real-time quantitative PCR and the 2(-Delta Delta C(T)) Method. Methods 25: 402-408, 2001.
21. Qi S, Xin Y, Guo Y, Diao Y, Kou X, Luo L and Yin Z: Ampelopsin reduces endotoxic inflammation via repressing ROS-mediated activation of $\mathrm{PI} 3 \mathrm{~K} / \mathrm{Akt} / \mathrm{NF}-\kappa \mathrm{B}$ signaling pathways. Int Immunopharmacol 12: 278-287, 2012.

22. Li X, Peng F, Xie C, Wu W, Han X and Chen L: (E)-3-(3,4 Dimethoxyphenyl)-1-(5-hydroxy-2,2-dimethyl-2H-chromen-6-yl) prop-2-en-1-one ameliorates the collagen-arthritis via blocking ERK/JNK and NF- $\kappa \mathrm{B}$ signaling pathway. Int Immunopharmaco 17: 1125-1133, 2013.

23. Sun GY, Yang HH, Guan XX, Zhong WJ, Liu YP, Du MY, Luo XQ, Zhou Y and Guan CX: Vasoactive intestinal peptide overexpression mediated by lentivirus attenuates lipopolysaccharide-induced acute lung injury in mice by inhibiting inflammation. Mol Immunol 97: 8-15, 2018.

24. Huang XT, Li C, Peng XP, Guo J, Yue SJ, Liu W, Zhao FY, Han JZ, Huang YH, Yang-Li, et al: An excessive increase in glutamate contributes to glucose-toxicity in $\beta$-cells via activation of pancreatic NMDA receptors in rodent diabetes. Sci Rep 7: 44120, 2017.

25. Huang XT, Liu W, Zhou Y, Sun M, Yang HH, Zhang CY and Tang SY: Galectin-1 ameliorates lipopolysaccharide-induced acute lung injury via AMPK-Nrf2 pathway in mice. Free Radic Biol Med 146: 222-233, 2020.

26. Hayes JD and Dinkova-Kostova AT: The Nrf2 regulatory network provides an interface between redox and intermediary metabolism. Trends Biochem Sci 39: 199-218, 2014.

27. Tian F, Wang Z, He J, Zhang Z and Tan N: 4-Octyl itaconate protects against renal fibrosis via inhibiting TGF- $\beta / \mathrm{Smad}$ pathway, autophagy and reducing generation of reactive oxygen species. Eur J Pharmacol 873: 172989, 2020.

28. Biswas SK and Lopez-Collazo E: Endotoxin tolerance: New mechanisms, molecules and clinical significance. Trends Immunol 30: 475-487, 2009.

29. Hussain S, Johnson CG, Sciurba J, Meng X, Stober VP, Liu C, Cyphert-Daly JM, Bulek K, Qian W, Solis A, et al: TLR5 participates in the TLR4 receptor complex and promotes MyD88-dependent signaling in environmental lung injury. Elife: Jan 28, 2020 (Epub ahead of print).

30. Fisher AB, Dodia C, Chatterjee S and Feinstein SI: A peptide inhibitor of NADPH oxidase (NOX2) activation markedly decreases mouse lung injury and mortality following administration of lipopolysaccharide (LPS). Int J Mol Sci 20: 2395, 2019

31. Hyam SR, Lee IA, Gu W, Kim KA, Jeong JJ, Jang SE, Han MJ and Kim DH: Arctigenin ameliorates inflammation in vitro and in vivo by inhibiting the PI3K/AKT pathway and polarizing M1 macrophages to M2-like macrophages. Eur J Pharmacol 708: 21-29, 2013

32. Zhao M, Li C, Shen F, Wang M, Jia N and Wang C: Naringenin ameliorates LPS-induced acute lung injury through its antioxidative and anti-inflammatory activity and by inhibition of the PI3K/AKT pathway. Exp Ther Med 14: 2228-2234, 2017.

33. Zhao M,Zhou A, Xu L and Zhang X: The role of TLR4-mediated $\mathrm{PTEN} / \mathrm{PI} 3 \mathrm{~K} / \mathrm{AKT} / \mathrm{NF}-\kappa \mathrm{B}$ signaling pathway in neuroinflammation in hippocampal neurons. Neuroscience 269: 93-101, 2014.

34. Niu T, Tian Y, Wang G, Guo G, Tong Y and Shi Y: Inhibition of ROS-NF- $\kappa$ B-dependent autophagy enhances Hypocrellin A united LED red light-induced apoptosis in squamous carcinoma A431 cells. Cell Signal 69: 109550, 2020.

35. Zhong W, Qian K, Xiong J, Ma K, Wang A and Zou Y: Curcumin alleviates lipopolysaccharide induced sepsis and liver failure by suppression of oxidative stress-related inflammation via PI3K/ $\mathrm{AKT}$ and NF- $\kappa \mathrm{B}$ related signaling. Biomed Pharmacother 83: 302-313, 2016

This work is licensed under a Creative Commons Attribution-NonCommercial-NoDerivatives 4.0 International (CC BY-NC-ND 4.0) License. 